\title{
IMPACT OF CONSTRUCTION PRACTICES ON THE ENVIRONMENT A CASE STUDY OF KANO STATE, NIGERIA
}

\author{
Aliyu, B.S., ${ }^{*}$ Moyi, M.Z., Fareed, L.Z., Sule, H.J., Nazifi, A.M., Bello, D.Y. and \\ Auwalu, B.A. \\ Nigeria Building and Road Research Institution (NBRRI), Northwest Zonal Office, Kano \\ * Correspondence author: abshehudawaki1@gmail.com
}

\section{ABSTRACT}

The Physical environment is being disturbed by numerous problems, including those caused by the constructions activities, such problems impacts on the environment right from the initial stage, operational and to the end of the life span of the built structure. The aim of the study was to suggest the main environmental impacts of construction in Kano state. About twenty six construction impacts were reveals from the past researches. However, all the impact was classified into nine main classes. Data for the study were collected from questionnaires and interviews survey administered to stakeholders of construction industry in Kano State. Data collected were analyzed and ranked using Relative Importance Index (RII), suggesting that they significantly impact on the environment thereby causing environmental degradation. Based on the results resource consumption was ranked highest among the major environmental impacts of constructing in Kano. The highest class, consist raw materials, water, fuel and electricity consumption. The paper concludes with recommendation which includes enforcement of extant rules, regulation and ethical code by government legislative on construction stakeholders, government should formulate and ensuring adequate use of construction design that will suite the environment in Kano. Also, all forms of construction practices should be subjected to an environmental impact assessment to determine the potential impacts and also formulate the ways to overcome it before execution. The study suggest also that, the chair personnel in construction companies should formulate some rules, code of conducts that will ensure good and fair sustainable construction practices in Kano.

Keywords: Construction Company, Construction Practices, Environmental Impact, Kano.

\section{INTRODUCTION}

So many researchers have been conducted in trying to investigate the environmental retardation. It has been the order of the day in our national dailies. According to Ofori (2005), the increase in population and the quest for development such as the built environment has resulted to ozone layer depletion, global warming, resource depletion and ecosystem destruction. Life is difficult to be imagining without construction process, and of course, without its means. The civilized world searches more rapid and comfortable means of construction. But all these means cause a lot of trouble for our environment. Dixon (2010), in past few decades' construction of roads has grown considerably because of the quick and flexible movement of goods. With an expanding market due to product specialization. There will be an increase in the demand for construction and transport techniques. There are however, several negative implications for the environment (air and noise pollution, human health and other more far-reading phenomena such as acidification, photochemical) air pollution and the green house effect, Dixon (2010).

Construction activities affect the environment through the life cycle of development. These impacts occur from initial work on site through the construction period, operational and final demolition when a building comes to an end of its life, Ofori (2015). According to Azqueta (1992), even through, construction project developments potentially contribute to the economic and social development, and enhancing both the standard of living and the quality of life, it is also associated with deterioration of the environment.

The focus of Nigerian constructions industry is generally on economic growth and improving the quality of life, of the people whilst environmental protection is utterly downgraded. 
But there are many concerns about it, and our endeavors to avoid these problems caused by construction activities to our precious environment. The construction industry has a signification impact, on the environment across a board spectrum of its activities during off site, on site and operational activities, which alter ecological integrity Uher (1999). According to Levin (1997), buildings are very large contributors to environmental deterioration. It is clear that actions are needed to make the built environment and construction activities more sustainable Hill and Bowen (1997); Barret et al; 1999; Cole (1999); Holmes and Hudson (2000); Morel et al., (2001); Schever et al., (2003). Hence, the analysis of the impact of the construction activities on the environment may need to look at a "Cradle to grave"(Ofori et al., (2001).

The construction industry has a major impact on the environment in its consumption of energy, both directly and embodied in the materials that is uses. It relies heavily on the natural environment for the supply of raw materials such as timber, sand and aggregates for the building process. The construction activities and raw materials extraction also contribute to the accumulation of pollutants in the atmosphere. According to Levin (1997), in the USA construction is responsible for 40 percent of atmospheric emissions, 20 percent of water effluents and 13 percents of other releases. Dust and other emissions include some toxic substances such as Nitrogen and sulphur oxide. They are release during the production and transportation of materials as well as from site activities and have caused serious threat to the natural environment, Spence and Mulligan, (1995); Ofori and Chan (1998); Rohracher (2001), Ofori and Kwame (2015).

Also, generating waste, building activities irreversible turn arable land into physical assets, such as building, roads, dams or other civil engineering projects (Spence and Mulligan (1995); Uher (1999); Langford et al., (1999). Arable land also get reduced through the extraction and mining of raw materials used in construction. More so, the conversion of trees into timber for construction have a greater impact of deforestation and at the end the burning of the remains lead to the direct global warming and atmospheric pollution, Ofori and Kwame (2015). Sources of Pollution and hazards from construction activities can be divided into seven major types, Chen et al. (2000). Dust, noises, harmful gasses, solid and liquid wastes, fallen objects, ground moments and others. Considered construction impacts under eight categories Chen et al., (2005): Soil and ground contamination, underground water contamination, construction and demolition waste, noise and vibration, dust, hazardous emissions and odours, wild life and natural features impacts and archaeology impacts. Negative impacts of the construction activities include waste production, mud, dust soil and water contamination and damage to public drainage systems, destruction of plants, noise traffic increase and parking space shortage and damage of public space, Cardos (2005). The environmental impacts of construction also include deforestation, air pollution, water and aquatic life destruction, degradation of soil through mining processes.

However, Eco-Management and Audit Scheme (EMAS) regulation (Gangollels, nod) provides a general and comprehensive breakdown of environmental aspect covering almost the afore mentioned aspects and this include: i. Emission to air, ii. Release to water iii. Avoidance, recycling, reuse, transportation and disposal of solid and other wastes iv. Contamination of land v. Use of raw-materials (energy) vi. Noise , Vibration and other local issues vii. Movements and transportation aspect viii. Environmental accidents and emergency situation ix. Effect on biodiversity.

\section{MATERIALS AND METHODS}

The research consists of quantitative and qualitative aspects. Where the quantitative aspect tries to investigate the real happening or facts and the qualitative aspect tries to assess the problem in view of opinion and attitude toward the object. During the quantitative study Architects, quantity Surveyors and civil engineers were selected. A population size of 80 was selected for the questionnaires survey.

\section{Data Collection}

The data were collected in two phases: The initial comprises of literature search for ideas and views on impacts of construction activities in some countries. It also include interviewing the practioners so as to validate the environmental impacts of construction obtained in the contained information of the other countries, literature in relation to that's of Nigeria, which resulted in coming up of 25 environmental impacts of construction.

However, the second phase engaged in producing of questionnaire in relations to the impacts of construction process on environment stated in the literature reviewed. 
The questionnaire was organized in the form of an importance scale (i.e. $4=$ most important, 3 $=$ more important, $2=$ important, $1=$ not important). Therefore participants are then asked to indicate by cycling columns, the relative importance of each of the impacts of construction practices on the environment. 80 Questionnaires are been distributed to respondents in Kano State of Nigeria.

\section{RESULTS}

Out of 80 total participants in the survey conducted $48 \%$ are architects, 33\% quantity surveyors and $19 \%$ are civil engineers. Also, about 25 causes of environmental downgrading were verified in the study and have been classified into main classes.
According to the result of the study the ranks of environmental impacts and the relative importance index by all participants were presented in table.

However, all the three classes of participants believe that the most important environmental impacts of construction processes in Kano are as follows:-

- Raw materials consumption/ intake.

- Noise and Vibration

- Deforestation

- Ecosystem tempering

- Water consumption

- Hydropower usage

- Desertification

- Machineries by products (Smoke)

\begin{tabular}{llll}
\multicolumn{2}{l}{ TABLE 1: Percentage of questionnaires distributed and response received } & \\
\hline RESPONDENTS & QUESTIONNAIRES & QUESTIONNAIRES & $\begin{array}{l}\text { PERCENTAGE OF } \\
\text { RESPONSES }\end{array}$ \\
& DISTRIBUTED & RETURNED & $84 \%$ \\
\hline Architects & 38 & 32 & $74 \%$ \\
Q. Surveyors & 27 & 20 & $80 \%$ \\
Civil Engineers & 15 & 12 & $\mathbf{8 0 \%}$ \\
TOTAL & $\mathbf{8 0}$ & $\mathbf{6 4}$ & \\
\hline
\end{tabular}

Table 2: Relative Importance Index (RII) and rank of Impacts of Construction Practices on the Environment In Kano According To The Three Groups Of Participants:

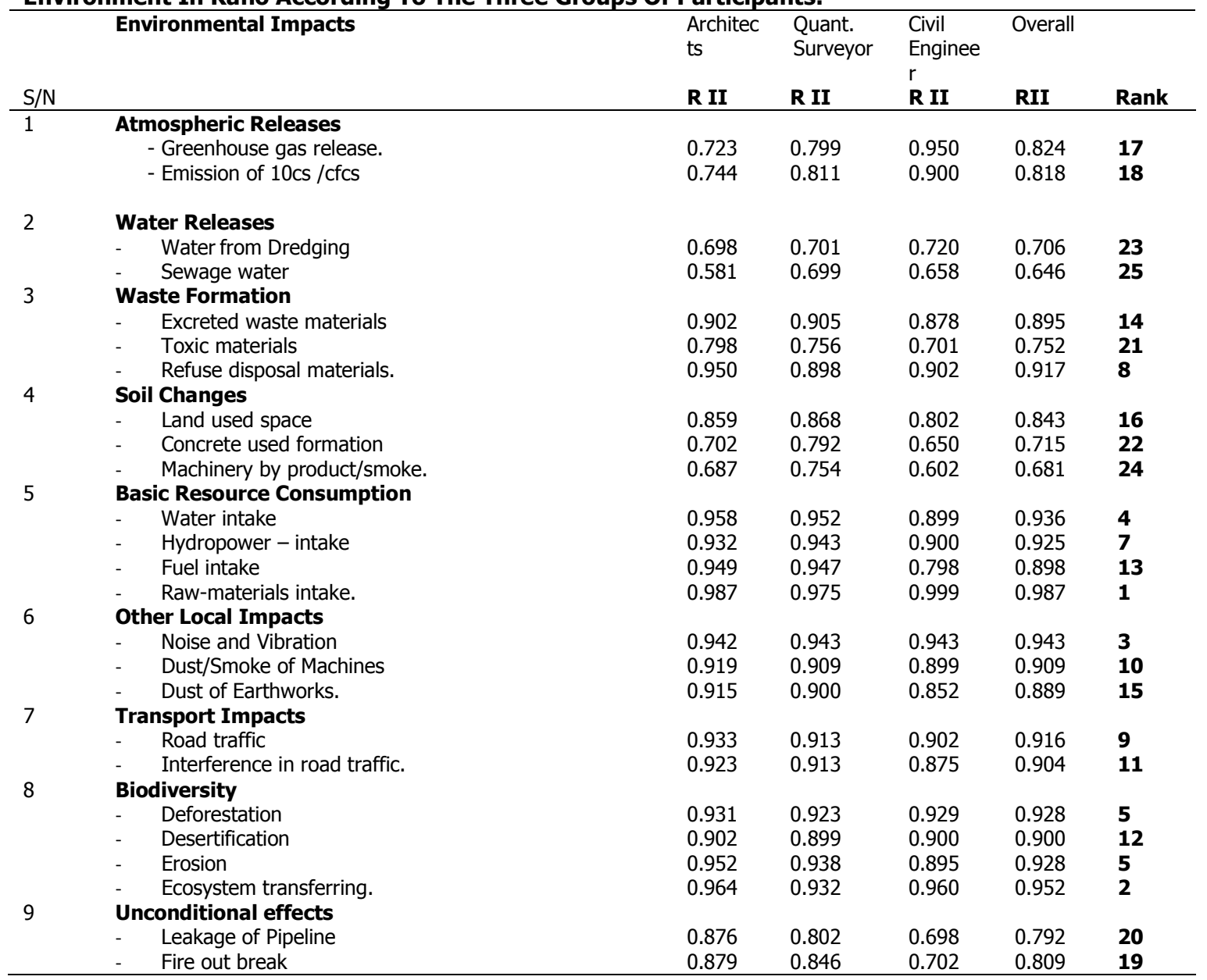




\section{PIE CHART DIAGRAM REPRESENTING THE SURVEY PARTICIPANT (\%)}

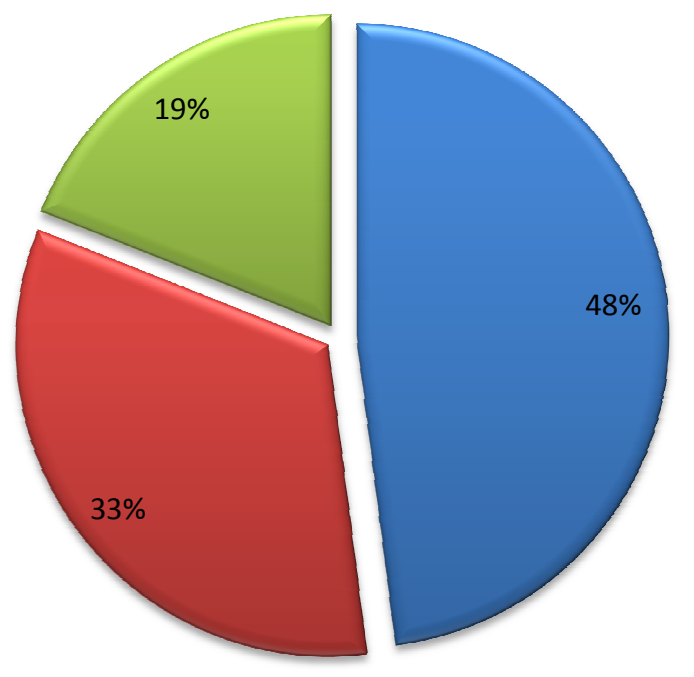

$\square$ ARCHITECTS

DQUANTITY SURV.

$\square$ CIVIL ENGINEERS

$\square$

\section{Consumption of Resource}

The consumption of resources class of impacts of construction practices on environment was ranked top most by all the participants collectively. Raw materials intake was the most important impacts of construction practices in Kano. The water, Hydropower and fuel consumption they are all among the most important environmental impacts of construction practices in Kano (Nigeria).

\section{Biodiversity}

Deforestation, ecosystem tempering, erosion activities are all biodiversity which are been ranked the second most important impacts of construction practices on the environment in Kano.

\section{Other Local Issues}

The local issues include, vibration and noise of machineries, smoke of machines, dust of earth activities are been classified, the third most important environmental impacts of construction in Kano.

\section{Transport Impacts}

The three classes of participants were collectively agreed on the transports impacts were ranked the fourth most important environmental impacts construction in Kano. And it consists of Road traffic, and all disturbances on road traffic activities

\section{Waste Pollution}

According to the survey, both the Architects and civil engineers ranked the waste generated from the construction activities as the most important impacts as such majority of wastes generated from construction activities are resulted from the production, transportation and the use of materials, Ofori and Chan (1998).

\section{Unconditional Effects}

These effects may include any disaster or unpredictable effects, such as leakage of pipe line, Fire outbreak, flooding in the environment and they were ranked as the seventh most important environmental impacts of construction processes in Kano.

\section{Soil Changes}

This class include, land used space, machineries smoke and concrete structure formation (bridges, culverts, building). The classes were ranked as the eight most important environmental impacts of construction in Kano.

\section{Water Releases}

The group was ranked the lowest by the three classes of the participants. The group consists of Sewage disposal into water, or oil spoilage, and dumping of refuse into water habitat to affect the life of aquatic animals. But due to lack of large water bodies in Kano, the effect terms to be minimal as such termed as the lowest environmental impacts of construction activities group, in Kano.

\section{Degree of agreement}

To determine whether there is a significant degree of agreement among the 3 groups (Architects, quantity surveyors, and structural engineers) Kendall's coefficient of concordance is used as a measure of agreement among raters. 
H0: There is no significant degree on agreement among Architects, Quantity Surveyors and Civil Engineers

H1: There is a significant degree of agreement among Architects, Quantity Surveyors and Civil Engineers

For all the environmental impact groups, the $\mathrm{p}$ values (Sig.) are greater than $a=0.05$ ( $a$ is the level of significance), the null hypothesis, $\mathrm{HO}$, is rejected. Thus, it can be said that there is a sufficient evidence to support the alternative hypothesis, $\mathrm{H} 1$. Therefore, there is a significant degree of agreement among the Architects, Quantity Surveyors and Civil Engineers regarding the level of each of the environmental impacts of construction activities in Kano State Nigeria.

The Kruskal-Wallis (KW) test was used to validate the result of the Kendall's coefficient of concordance test. KW test is a statistical test that can be used to compare the ranks means between two or more samples. This test is used in order to check out if there are any significant differences in the point of view of the respondents (Architects, Quantity Surveyors and Civil Engineers) regarding the level of each of the environmental impacts of construction activities.

$\mathrm{HO}$ : There is no significant difference between the response of the Architects, Quantity Surveyors and Civil Engineers

$\mathrm{H} 1$ : There is a significant difference between the response of the Architects, Quantity Surveyors and Civil Engineers

For all the environmental impacts groups, the $\mathrm{p}$ value (Sig.) for each group is greater than $a=0.05$ ( $a$ is the level of significance), hence it can be concluded that there is no significant difference between the three group of practioners' responses regarding the environmental impacts of construction activities. This result validates the previous result. Therefore, it can be reliably stated that the three

\section{REFERENCES}

Azqueta, D. (1992). Social project and environmental impact assessment: a necessary but complicated theoretical bridge, in Development policy Review, Vol.10, pp.255-270.

Barrett, P. S., Sexton, M.G. and Green, L. (1999). Integrated delivery system for sustainable construction', in Building Research and information, Vol. 27, No. 6, pp.397-404.

Dixon, W. (2010). The Impacts of Construction and the Built Environment' in a Briefing Note Version 1: December 2010. groups of respondents' agree with each other in terms of environmental impacts of construction activities.

\section{CONCLUSION AND RECOMMENDATION}

Built environment and its interactions with the natural environment is complex and have a massive impact on the world around us. However, this research focused on the impacts of construction practices on the Kano State's environment. The research was conducted based on the views of Architects, quantity surveyors and civil engineers. According to the study from the total of 25 impacts of construction practices on the environment the most important impacts are consumption of resources, vibration of machineries, deforestation, tempering with ecosystem, water intake, hydropower, soil changes, waste formation etc. All the 25 impacts where classified into nine classes. From the result it is also shown that all the three class of the participants believed that the consumption of resources is the most important impacts followed by biodiversity effects, on the environments.

The paper recommended that, enforcement of extant rules, regulation and ethical code by government legislative on construction stakeholders, government should formulate and ensuring adequate use of construction design that will suite the environment in Kano. Also, all forms of construction practices should be subjected to an environmental impact assessment to determine the potential impacts and also formulate the ways to overcome it before execution. The study suggest also that, the chair personnel in construction companies should formulate some rules, code of conducts that will ensure good and fair sustainable construction practices in Kano.

Ofori, S., Kwame, S. (2015). Impact of construction activities on the environment in Ghana. Journal of Environment and Earth Science, Vol.5, No. 3

Curwell, S. and Cooper, I. (1998). The implications of urban sustainability' in Building Research and Information, Vol. 26, No. 1, pp.17-28.

Hill, R..C. and Bowen, P.A. (1997). Sustainable construction: principles and a framework for attainment', in Construction Management and Economics, Vol. 15, pp. 223-239. 
Holmes, J. and Hudson, G. (2000). An evaluation of the objectives of the BREEAM scheme for offices: a local case study', in proceedings of Cutting Edge 2000, RICS Research Foundation, RICS, London.

Kein, A.T.T., Ofori, G. and Briffett, C. (1999). ISO 14000: its relevance to the construction industry of Singapore and its potential as the next industry milestone', in construction Management and Economics, Vol. 17, pp. 449-461.

Langford, D.A., Zhang, X.Q., and Maver, T.,(1999). Design and managing for sustainable buildings in the UK', in profitable partnering in construction procurement, CIB W92 (Procurement Systems) and CIB23 (Culture in Construction), Joint Symposium, S.O. Ogunlana, (Ed.), E \& FN Spon, London, pp.373-382.

Ofori, G. and Chan, P. (1998). Procurement methods and contractual provisions for sustainability in construction', in
Proceedings of Construction and the Environment: CIB World Building Congress.

Rohracher, H. (2000). Managing the technological transition to sustainable construction of buildings: a sociotechnical perspective', in Technology Analysis and Strategic Management, Vol. 13 , No. 1 pp. 137-150.

Sterner, E. (2002). Green procurement of buildings: A Study of Swedish clients' considerations, in construction Management and Economics, Vol. 20, pp. 21-30.

Teo, M.M.M. and Loosemore, M. (2001). A theory of waste behavior in the construction industry, in construction Management and Economics, Vol. 19, pp. 741-751.

Uher, T.E. (1999). Absolute indicator of sustainable construction', COBRA 1999.

World watch Institute (2003). Sustainable facilities: building material selection. 